\title{
Breeding of red clover for ingredient in functional food
}

\author{
Giedrius PETRAUSKAS - Eglè NORKEVIČIENÉ - Kristina JAŠKŪNĖ \\ Institute of Agriculture, Lithuanian Research Centre for Agriculture and Forestry, Instituto a. 1, Akademija, \\ Kèdainiai distr. Lithuania; E-mail: giedrius.petrauskas@lammc.lt; egle.norkeviciene@lammc.lt; kristina. \\ jaskune@lammc.lt
}

Keywords: autochthonous red clover, health-promotion substances, $\mathbf{G} \times \mathbf{E}$ interaction

\section{Introduction}

Autochthonous red clover (Trifolium pratense L.) is characterized as ecologically and economically important relative of red clover cultivars. As other legumes, red clover known not only as highly nutritious food component but also as containing different minerals as well as various secondary metabolites and amino acids. Trifolium pratense was found to be rich source of isoflavonoids, flavonoids, coumarin derivatives, cyanogenic glyco-sides, volatile oil, saponins, and trace vitamins (Booth et al., 2006). Due to that, red clover may supply food with the many bioactive compounds required in human diet and could be used as ingredient in functional food. However, nutritional, mineral and phytochemical value depends within and among species (Butkute et al., 2019). It is of a key importance to identify a new breeding material that possesses high levels of bioactive compounds and amino acids, would be resistant to pests and diseases thus complementing the gene pool of red clover and it could be found in situ where high biodiversity is prevalent.

\section{Materials and methods}

Red clover seeds were collected from 48 populations in different geographical areas across Lithuania in 2016. The study involved 12 cultivars of red clover (Trifolium pratense L.) bred in different countries and 48 breeding lines (populations) of Lithuanian origin. Endocalcari - Epihypogleyic Cambisol (RDg4-k2) with a texture of moderately heavy loam predominated in the fields. Each genotype was sown in plot trial with three replications in randomized complete block design. Morphological parameters were evaluated for whole plant, stems, and leaves. Additionally, crude protein $(\mathrm{CP})$, crude fiber (CF) and water-soluble carbohydrates (WSC) of red clover were evaluated.

\section{Results and discussion}

Red clover populations and cultivars were divided in three groups based on time of flowering in 2018: early (from 15 till 24 of May), medium (from 25 till 30 of May), late (from 1 till 15 of June). There were 17 early, 16 medium and 15 late red clover populations. Principal component analysis of red clover populations $(n=55)$ based on morphological and economically important traits $(\mathrm{p}=13)$ have shown high phenotypic diversity within the populations and only three out of total (no. 2206, 2875, 2902) were significant different at $95 \%$ level (Fig. 1). These results revealed that diversity among populations is low despite existing high phenotypic variability within populations.

Crude protein (CP), crude fiber (CF) and water-soluble carbohydrates (WSC) contents in red clover populations and cultivars were highly variable. $\mathrm{CP}$ varied from $123 \mathrm{~g} \mathrm{~kg}^{-1}$ (no. 


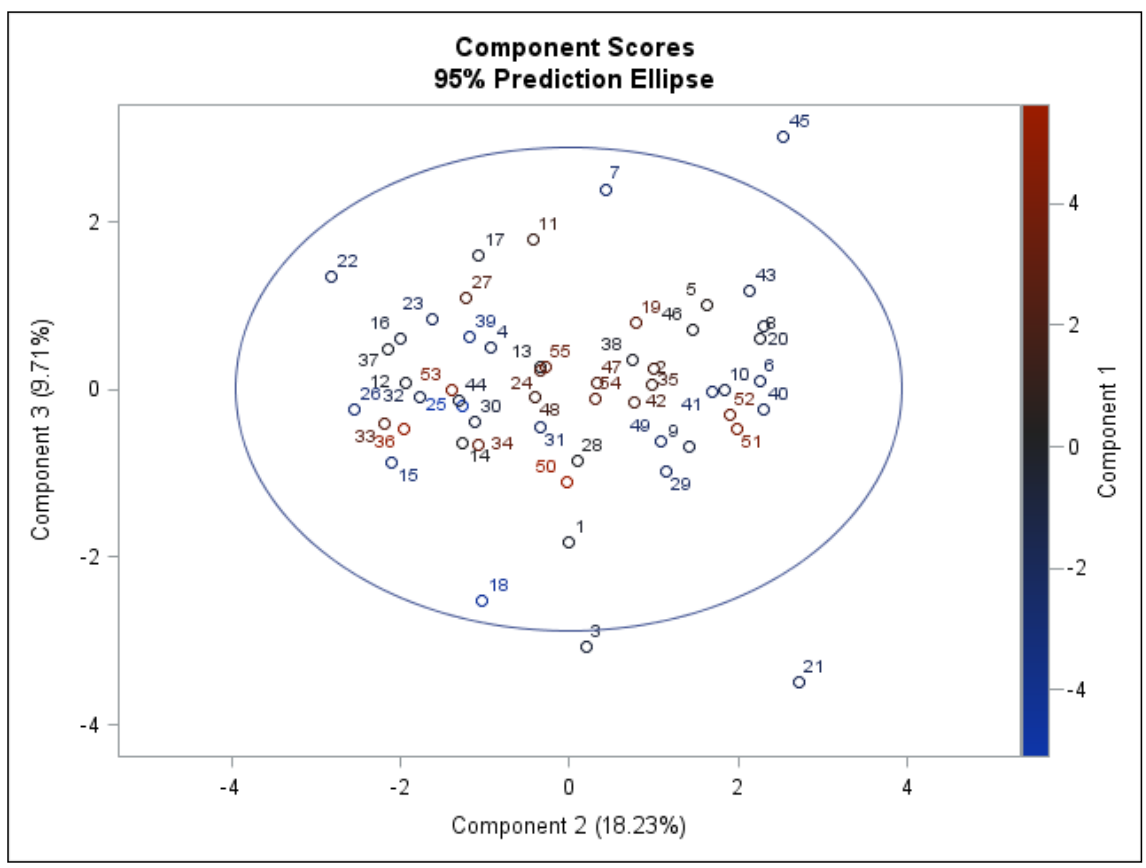

Figure 1: Principal component analysis of red clover populations $(n=55)$ based on morphological and economically useful traits ( $p=13$ ). The first, second and third PC axes explain $45.53 \%, 18.23 \%$ and $9.71 \%$, respectively, of the variation in the data set.

2897) to $197 \mathrm{~g} \mathrm{~kg}^{-1}$ (no. 2887), $\mathrm{CF}$ - from $243 \mathrm{~g} \mathrm{~kg}^{-1}$ (no. 2887) to $330 \mathrm{~g} \mathrm{~kg}^{-1}$ (no. 2885) and WSC - from $59 \mathrm{~g} \mathrm{~kg}^{-1}$ (no 2900) to $111 \mathrm{~g} \mathrm{~kg}^{-1}$ ('Kiršinai'). Based on this data, wild red clover populations no. $2875,2885,2887$ etc. had good fodder quality values thus could be selected as important gene donors for breeding of new cultivars.

\section{Conclusions}

Results shown that there is high variation in morphology of red clover. However, data based on morphological and fodder quality shown that several populations (no. 2875, 2885,2887 and etc.) are valuable breeding material and might be used for functional food as well.

\section{Acknowledgement}

This study is being funded through the long-term research program "Genetics and purposeful change of genotypes of agricultural and forest plants" implemented by the Lithuanian Research Centre for Agriculture and Forestry.

\section{References}

Booth, N.L., Overk, C.R., Yao, P., Burdette, J.E., Nikolic, D., Chen, S.N., Bolton, J.L., van Breemen, R.B., Pauli, G.F., Farnsworth, N.R. (2006): The chemical and biologic profile of a red clover (Trifolium pratense L.) phase II clinical extract. Journal of alternative and complementary medicine. 12(2), 133-9. https://doi. org/10.1089/acm.2006.12.133

Butkutè, B., Taujenis, L., Norkevičienė, E. (2019). Small-Seeded Legumes as a Novel Food Source. Variation of Nutritional, Mineral and Phytochemical Profiles in the Chain: Raw Seeds-Sprouted Seeds-Microgreens. Molecules, 24(1): 133. https://doi.org/10.1089/acm.2006.12.133 